\title{
Effect of Selenium on HLA-DR Expression of Thyrocytes
}

\author{
Csaba Balázs and Viktória Kaczur \\ Department of Medicine and Endocrinology, Polyclinic of the Hospitaller Brother of St. John of God in Budapest, \\ Budapest 1027, Hungary
}

Correspondence should be addressed to Csaba Balázs, drbalazs@irgalmas.hu

Received 13 September 2011; Revised 28 October 2011; Accepted 31 October 2011

Academic Editor: Juan-Manuel Anaya

Copyright (C) 2012 C. Balázs and V. Kaczur. This is an open access article distributed under the Creative Commons Attribution License, which permits unrestricted use, distribution, and reproduction in any medium, provided the original work is properly cited.

\begin{abstract}
Autoimmune thyroid diseases (ATDs) represent the most frequent forms of the organ-specific autoimmune thyroid disorders that result from interaction between genetic and environmental factors. Selenium has been shown to exert a beneficial effect on the autoimmune thyroiditis. In spite of therapeutical effect of selenium on autoimmunity, the mechanism of its action has not been revealed. Objective. To determine whether selenium in vitro thyrocytes cultures are able to influence the HLA-DR molecule expression of human thyrocytes and production of free oxygen radicals. Method. Thyrocytes were prepared from human thyroid gland and cultured in vitro in the presence of interferon- $\gamma$ and sodium selenite. The expression of HLA-DR molecules induced by interferon- $\gamma$ in the presence of sodium selenite of various concentration was measured by fluorescence-activated cell sorter. Results. Selenium has a dose-dependent inhibitory effect on the expression of HLA-DR molecules of thyrocytes induced by interferon- $\gamma$. This effect of selenium was in the inverse correlation with antioxidative capacity. Conclusion. Beneficial effect of selenium on autoimmune mechanism is a complex mechanism in which the inhibitory effect on HLA-DR molecule expression and antioxidative capacity are involved into therapy of autoimmune thyroiditis.
\end{abstract}

\section{Introduction}

Recently published clinical studies on possible effects of selenium (Se) in autoimmune thyroiditis evoked exciting discussion. The conflicting data were published on effect of Se; the one part of investigators provided evidences that Se intakes may be beneficial with respect to autoimmune diseases [1$7]$, the others were not able to show the significant effect of Se on autoimmune thyroiditis $[8,9]$. Furthermore, the authors who published the beneficial effect of Se on the levels of autoantibodies, advised to use Se therapy for patients with autoimmune thyroiditis (AIT) $[1,4,10]$. Recently, we published our prospective placebo-controlled prospective study including 132 patients with autoimmune thyroiditis [4]. L-thyroxine substitution therapy was made in both groups and the level of TSH remained in the normal range. Se therapy was continued by L-seleno-methionine (per os $2 \times 100 \mu \mathrm{g} /$ day) for one year. The level of Se in the untreated patients' sera was significantly lower than in treated patients and controls, and after three-month therapy with it, Se was normalized.
The titer of antithyroid antibodies (mostly the anti-TPO) significantly decreased at the end of study. An inverse correlation was found between antioxidant capacity and level of anti-TPO antibodies. This observation suggests that Se deficiency by itself might be responsible for the precipitation of inflammatory process. Although the precise mechanisms of action and the possible targets of Se have not been clarified yet, the beneficial influence of Se can be explained by different points of views. Growing evidence supports that the selenium-containing enzymes and their antioxidant capacity somehow modify the autoimmune mechanism [11-15]. Previously, it was published that unlike in thyroids from healthy individuals thyroid epithelial cells from patients with AITD were able to express HLA class II antigen molecules similar to normally expressed on antigen presenting cells (APCs) such as macrophages and dendritic cells [16-19]. The aberrant expression of HLA Class II molecules on thyroid cells may initiate and perpetuate thyroid autoimmunity via direct autoantigen presentation. We removed the repeated references from the highlighted part. Please check similar 
TABLE 1: Investigation of HLA-DR expression on thyrocytes induced by IFN- $\gamma$ in the absence and presence of selenium. Figures in the table represent mean percentage DR positive human thyroid cells \pm SD. All experiments were made in triplicate. ns. = not significant.

\begin{tabular}{lcccc}
\hline Culture of human thyrocytes & \multicolumn{3}{c}{ Expression of HLA-DR on thyrocytes (\%) } \\
\hline Culture media $(n=4)$ & $3.7 \pm 2.4$ & \multirow{2}{*}{$P<0.001$} & & \\
IFN- $\gamma(100 \mathrm{U} / \mathrm{mL})$ & $35.2 \pm 5.2$ & & n.s & \\
IFN- $\gamma(100 \mathrm{U} / \mathrm{mL})+$ sodium selenite $(10 \mathrm{nM} / \mathrm{mL})(n=3)$ & $33.2 \pm 14.7$ & & \\
IFN- $\gamma(100 \mathrm{U} / \mathrm{mL})+$ sodium selenite $(50 \mathrm{nM} / \mathrm{mL})(n=3)$ & $26.4 \pm 12.7$ & & \\
IFN- $\gamma(100 \mathrm{U} / \mathrm{mL})+$ sodium selenite $(100 \mathrm{nM} / \mathrm{mL})(n=3)$ & $11.5 \pm 5.2$ & & & \\
\hline
\end{tabular}

cases throughout the paper. Previously we provided evidence for the role of HLA-DR expression on thyrocytes induced by interferon- $\gamma($ IFN- $\gamma)$ and its modification by methimazole which has a significant anti-oxidative capacity [20]. It was assumed that the Se, like methimazole, can modify the expression of HLA-DR molecules on thyrocytes culture in the presence of Se; therefore, we made in vitro experiments using human thyrocytes cultures to study this hypothesis.

\section{Materials and Methods}

We cultured human thyrocytes and analyzed HLA-DR antigen expressions induced by IFN- $\gamma$ in the various concentrations of sodium selenite (Sigma) in culture media by previously published method [16]. Briefly, thyroid epithelial cells were separated from surgical specimens. $4-6 \times 10^{6}$ cells were obtained from $10 \mathrm{~g}$ of tissue with viability of $>90 \%$ which was determined by trypan blue exclusion. $2 \times 10^{5}$ cells were placed in each well of a 24-well Costar culture plate and cultured in minimum essential medium containing $15 \%$ fetal calf serum (FCS) with $0.2 \%$ sodium bicarbonate either alone (control wells) or in the presence of IFN- $\gamma$ (Hoffmann-La Roche), and to other wells 10.0, 50.0, and $100 \mathrm{nmol} / \mathrm{mL}$ of sodium selenite (Sigma) were added. In most of experiments, thyrocytes were cultured for 3 days and then detached by $0.2 \%$ trypsin. HLA-DR expression was investigated initially ( 0 day) and on day 3 and 7 of culture. Cells were recovered in $\mathrm{Ca}^{++}$and $\mathrm{Mg}^{++}$free EGTA solution with rubber policeman. The detached cells were resuspended in RPMI containing 10\% FCS, $10 \mathrm{mM}$ HEPES (Sigma). For indirect immunofluorescence, cells were resuspended in $200 \mu \mathrm{L}$ RPMI (Sigma) containing $10 \%$ FCS, in $10 \mathrm{mM}$ HEPES and were incubated for $30 \mathrm{~min}$ at $4^{\circ} \mathrm{C}$ with $5.0 \mu \mathrm{L}$ monoclonal anti-DR framework antibody (DAKO). The cells were washed twice and the pellet incubated for $30 \mathrm{~min}$ at $4{ }^{\circ} \mathrm{C}$ with $1: 100$ dilution of FITC-conjugated rabbit anti-mouse immunoglobulin (Cooper Biomedical, Inc., Malvern, PA). After two washes, the cells were analyzed in fluorescenceactivated cell sorter (FACS III, Beckton-Dickinson Co., Sunnyvale, CA). All experiments were made in triplicate. The total antioxidant status (TAS) was determined by Randox kit (Randox Laboratories Ltd, Crumlin, UK) $[4,12,14]$.

2.1. Statistical Methods. The computerized program "Stat View" (Version 4.5, SAS Institute Corp., North Carolina, USA) was used for evaluating data. Descriptive statistics,
Pearson's chi-square test, Fisher's exact test, and ANOVA analysis were performed. Values of $P<0.05$ were considered as significant.

\section{Results}

We found that IFN- $\gamma(100 \mathrm{U} / \mathrm{mL})$ was able to induce a significant stimulation of expression of HLA-DR molecules in thyrocytes (Table 1) $(35.2 \pm 15.2$ versus $3.7 \pm 2.4, P<$ $0.001)$. The peak of HLA-DR expression was at day three and then decreased abruptly. Therefore, we tested the expression of HLA-DR positive cells induced by IFN- $\gamma$ at day three in absence and presence of Se of various concentrations. Se in two different concentrations $(50 \mathrm{nM} / \mathrm{mL}$ and $100 \mathrm{nM} / \mathrm{mL}$, resp.) significantly inhibited the expression of HLA-DR positive cells induced by IFN- $\gamma$ (Table 1). If we added the Se to thyrocytes cultures after or before exposition of IFN- $\gamma$, there were not observed significant changes in HLA-DR expression. Time-dependent effect of sodium selenite $(100 \mathrm{nM} / \mathrm{mL})$ on IFN- $\gamma$-induced HLA-DR expression $(100 \mathrm{U} / \mathrm{mL})$ was on Figure 1. Then we studied the possible connection with HLADR expression on thyrocytes and antioxidant capacity of Se and found an inverse correlation between antioxidant status and expression of HLA-DR positive cells $(r=-0.72, P<$ 0.01) (Figure 2).

\section{Discussion}

The trace element of Se plays an important role in the thyroid gland under physiological conditions and in diseases as well. Se supplementation decreased inflammatory activity in patients with autoimmune thyroiditis, and the reduction of titres of anti-TPO antibodies was correlated with serum levels of Se $[2,4,6,7]$. Convincing observation was published for beneficial effect of Se in a patent with autoimmune thyroiditis when a marked decrease in thyroid 18FDG uptake after Se supplementation was found [21]. In spite of great efforts, the precise mechanism of Se has not yet been clarified. The role of antioxidant property of Se was published to be involved into beneficial effect in autoimmune thyroiditis [12-15]. Previously, we found that methimazole proved to have antioxidant capacity decreased the expression of HLA-DR molecules on the surface of thyrocytes [20]. Our experiments confirmed that the Se has a significant radical scavenging effect and the decrease the expression of HLA-DR molecules induced by IFN- $\gamma$ was in an inverse correlation with 


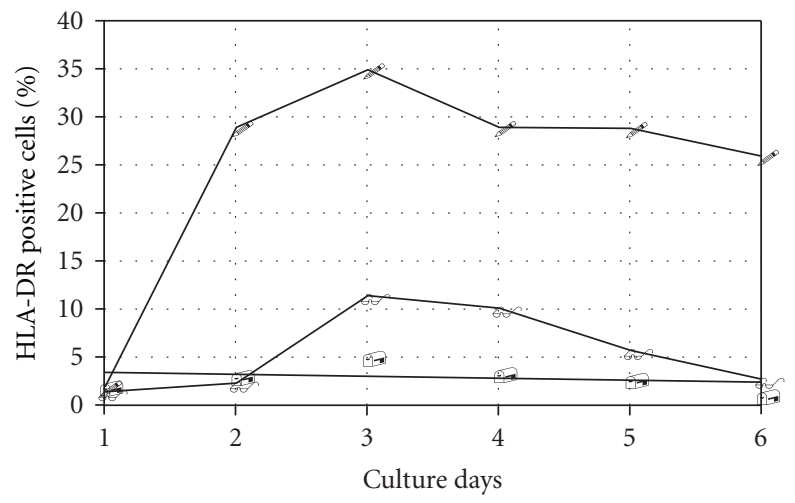

FIGURE 1: Time-dependent effect of sodium selenite $(100 \mathrm{nM} / \mathrm{mL})$ on IFN- $\gamma(100 \mathrm{U} / \mathrm{mL})$ induced HLA-DR expression. (i) Dots: HLADR expression without sodium selenite. (ii) Square: HLA-DR expression with sodium selenite (100 nM/mL). (iii) Filled square: HLA-DR expression with sodium selenite.

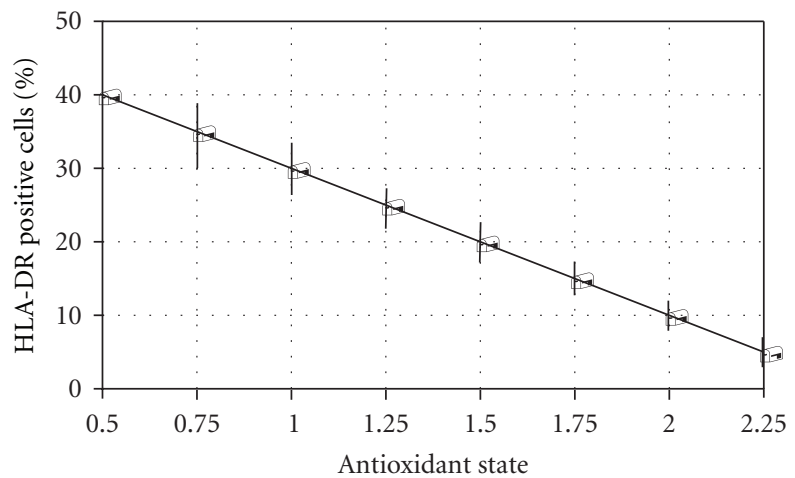

FIGURE 2: Study of connection between antioxidant status and expression of HLA-DR positive cells. Bars show the \pm SD, $r=-0.72$.

antioxidative capacity of thyrocytes supernatant. The exogenous factors including iodine and oxidative stress have been published to be precipitating factors in genetically susceptible individuals $[5,14,22-26]$. The antigenicity of thyroid autoantigens (thyroglobulin and TPO) is increased after iodine exposition. The iodine is able to increase the amount of free radicals which are produced in the process of physiological hormonogenesis in the thyroid gland. In addition, there are accumulating data for antiviral capacity of Se. Both epidemiological and in vitro data demonstrated that Se deficiency might be important in viral infections as well [11]. Since the viruses have been published to induce IFN$\gamma$, consequently HLA-DR expression, therefore, it is hypothesized that the trigger in autoimmune thyroiditis might be a virus infection [27-29]. Nowadays, the suggestion of viral origin of autoimmunity appears to be a speculation; however, the "selenium story" might open a new window not only for better understanding of beneficial effect of Se in autoimmune thyroiditis but also in the research of origin of autoimmunity $[9,11-13,15,22]$. A new perspective has been opened by the investigations of Se on the role of $\mathrm{T}$ regulatory cells (Treg) with CD4CD25 FoxP3 markers $[24,25,30$, 31]. Accumulating data demonstrated that deficiency of
$\mathrm{CD} 4^{+} \mathrm{CD} 25^{+}$Treg cells was closely correlated with development of ATD [24, 25, 30, 31]. Recently, it was published in animal experiments that the CD4CD25 FoxP3 T cells displayed preventive effect on development of ATD [26]. Surprisingly, Se upregulated $\mathrm{CD} 4{ }^{+} \mathrm{CD} 25^{+}$regulatory $\mathrm{T}$ cells in iodine-induced autoimmune thyroiditis model of NOD.H$2^{\mathrm{h} 4}$ mice [24]. Our observation and experiments provide evidence that Se has a complex effect on immune system including decreased expression on HLA-DR molecules and by this way can prevent the induction and perpetuation of autoimmune thyroid processes.

\section{Conclusions}

Se has a dose-dependent inhibitory effect on the expression of HLA-DR molecules of thyrocytes induced by interferon$\gamma$. This effect of selenium was in the inverse correlation with anti-oxidative capacity. Inhibitory effect of Se on HLA-DR molecule expression and antioxidative capacity is involved into therapy of autoimmune thyroiditis. Our in vitro study provided evidence that the free radical scavenging effect of Se plays an important role in the therapy and the prevention of autoimmunity. 


\section{Abbreviations}

AIT: Autoimmune thyroiditis

ATD: Autoimmune thyroid disease

HLA: Human leucocyte antigen DR locus

IFN- $\gamma$ : Interferon- $\gamma$

MHC: Major histocompatibility complex

Se: Selenium

TAS: Total antioxidant state

TPO: Thyroid peroxidase

APCs: Antigen presenting cells.

\section{Acknowledgment}

To the memory of my best colleague and friend Prof. Nadir R. Farid and Prof. V. Kaczur who (died due to an accident).

\section{References}

[1] R. Gärtner, B. C. H. Gasnier, J. W. Dietrich, B. Krebs, and M. W. A. Angstwurm, "Selenium supplementation in patients with autoimmune thyroiditis decreases thyroid peroxidase antibodies concentrations," Journal of Clinical Endocrinology and Metabolism, vol. 87, no. 4, pp. 1687-1691, 2002.

[2] G. J. Beckett and J. R. Arthur, "Selenium and endocrine systems," Journal of Endocrinology, vol. 184, no. 3, pp. 455-465, 2005.

[3] L. H. Duntas, "The role of selenium in thyroid autoimmunity and cancer," Thyroid, vol. 16, no. 5, pp. 455-460, 2006.

[4] C. Balázs and J. Fehér, "The effect of selenium therapy on autoimmune thyroiditis," CEMED, vol. 3, pp. 269-277, 2009.

[5] V. F. H. Brauer, U. Schweizer, and J. Köhrle, "Selenium supplementation and goitre prevalence in borderline iodine sufficiency," European Journal of Endocrinology, vol. 155, pp. 807812, 2006.

[6] L. H. Duntas, "Environmental factors and autoimmune thyroiditis," Nature Clinical Practice Endocrinology and Metabolism, vol. 4, no. 8, pp. 454-460, 2008.

[7] R. Gärtner and L. H. Duntas, "Effects of selenium supplementation on TPOAb and cytokines in acute autoimmune thyroiditis," Thyroid, vol. 18, no. 6, pp. 669-670, 2008.

[8] G. Karanikas, M. Schuetz, S. Kontur et al., "No immunological benefit of selenium in consecutive patients with autoimmune thyroiditis," Thyroid, vol. 18, no. 1, pp. 7-12, 2008.

[9] W. Bonfig, R. Gärtner, and H. Schmidt, "Selenium supplementation does not decrease thyroid peroxidase antibody concentration in children and adolescents with autoimmune thyroiditis," The Scientific World Journal, vol. 10, pp. 990-996, 2010.

[10] E. E. Mazokopakis, J. A. Papadakis, M. G. Papadomanolak$i$ et al., "Effects of 12 months treatment with L-selenomethionine on serum anti-TPO levels in patients with Hashimoto's thyroiditis," Thyroid, vol. 17, no. 7, pp. 609-612, 2007.

[11] M. P. Rayman, A. J. Thompson, and B. Bekaert, "Randomized controlled trial of the effect of selenium supplementation on thyroid function in the elderly in the United Kingdom," American Journal of Clinical Nutrition, vol. 87, no. 2, pp. 370-378, 2008.

[12] C. L. Burek and N. R. Rose, "Autoimmune thyroditis and ROS," Autoimmunity Reviews, vol. 7, p. 5537, 2008.

[13] M. G. Boosalis, "The role of selenium in chronic disease," Nutrition in Clinical Practice, vol. 23, no. 2, pp. 152-160, 2008.
[14] W. P. Faulk and J. A. McIntyre, "Prologue to autoimmunity forum: autoimmunity reviews on redox signaling," Autoimmunity Reviews, vol. 7, no. 7, pp. 515-517, 2008.

[15] C. Perricone, C. De Carolis, and R. Perricone, "Glutathione: a key player in autoimmunity," Autoimmunity Reviews, vol. 8, no. 8, pp. 697-701, 2009.

[16] E. Bodolay, G. Szegedi, and P. Suranyi, "Expression of HLADR antigens by thyroid cells: the effect of Graves' IgG," Immunology Letters, vol. 15, no. 1, pp. 77-81, 1987.

[17] M. Kuang, S. Wang, M. Wu, G. Ning, Z. Yao, and L. Li, "Expression of IFN $\alpha$-inducible genes and modulation of HLADR and thyroid stimulating hormone receptors in Graves' disease," Molecular and Cellular Endocrinology, vol. 319, no. 1-2, pp. 23-29, 2010.

[18] L. Muixí, I. Alvarez, and D. Jaraquemada, "Chapter 6 peptides presented in vivo by HLA-DR in thyroid autoimmunity," Advances in Immunology, vol. 99, pp. 165-209, 2008.

[19] T. Hanafusa, R. Pujol Borrell, and L. Chiovato, "Aberrant expression of HLA-DR antigen on thyrocytes in Graves' disease: relevance for autoimmunity," Lancet, vol. 2, no. 8359, pp. 1111-1115, 1983.

[20] C. Balázs, E. Kiss, A. Leövey, and N. R. Farid, “The immunosuppressive effect of methimazole on cell-mediated immunity is mediated by its capacity to inhibit peroxidase and to scavenge free oxygen radicals," Clinical Endocrinology, vol. 25, no. 1, pp. 7-16, 1986.

[21] L. Giovanella, S. Surlano, and L. Ceriani, "Decline in thyroid 18fluorodoxyglucose up take associated with selenium supplementation in a patent with autoimmune thyroiditis," Thyroid, vol. 19, pp. 1291-1292, 2008.

[22] J. Köhrle, F. Jakob, B. Contempré, and J. E. Dumont, "Selenium, the thyroid, and the endocrine system," Endocrine Reviews, vol. 26, no. 7, pp. 944-984, 2005.

[23] A. A. Zeitlin, J. M. Heward, P. R. Newby et al., "Analysis of HLA class II genes in Hashimoto's thyroiditis reveals differences compared to Graves' disease," Genes and Immunity, vol. 9, no. 4, pp. 358-363, 2008.

[24] H. Xue, W. Wang, Y. Li et al., "Selenium upregulates $\mathrm{CD} 4{ }^{+} \mathrm{CD} 25^{+}$regulatory $\mathrm{T}$ cells in iodine-induced autoimmune thyroiditis model of NOD.H-2(h4) mice," Endocrine Journal, vol. 57, no. 7, pp. 595-601, 2010.

[25] B. Zhang, C. Sun, Y. Qu et al., "Deficiency of mouse $\mathrm{CD} 4{ }^{+} \mathrm{CD} 25^{+} \mathrm{Foxp}^{+}$regulatory $\mathrm{T}$ cells in xenogeneic pig thymus-grafted nude mice suffering from autoimmune diseases," Cellular \& molecular immunology, vol. 5, no. 5, pp. 325-332, 2008.

[26] Y. C. Kong, "Experimental autoimmune thyroiditis in the mouse," Current Protocols in Immunology, vol. 15, pp. 15-27, 2007.

[27] H. H. Niller, H. Wolf, and J. Minarovits, "Regulation and dysregulation of Epstein-Barr virus latency: implications for the development of autoimmune diseases," Autoimmunity, vol. 41, no. 4, pp. 298-328, 2008.

[28] S. Verma, Y. Molina, Y. Y. Lo et al., "In vitro effects of selenium deficiency on West Nile virus replication and cytopathogenicity," Virology Journal, vol. 5, article 66, 2008.

[29] J. L. Leite, N. E. Bufalo, R. B. Santos, J. H. Romaldini, and L. S. Ward, "Herpesvirus type 7 infection may play an important role in individuals with a genetic profile of susceptibility to Graves' disease," European Journal of Endocrinology, vol. 162, no. 2, pp. 315-321, 2010. 
[30] J. Mjösberg, G. Berg, J. Ernerudh, and C. Ekerfelt, " $\mathrm{CD} 4{ }^{+} \mathrm{CD} 25^{+}$regulatory $\mathrm{T}$ cells in human pregnancy: development of a Treg-MLC-ELISPOT suppression assay and indications of paternal specific Tregs," Immunology, vol. 120, no. 4, pp. 456-466, 2007.

[31] F. W. Hoffmann, A. C. Hashimoto, L. A. Shafer, S. Dow, M. J. Berry, and P. R. Hoffmann, "Dietary selenium modulates activation and differentiation of $\mathrm{CD} 4^{+} \mathrm{T}$ cells in mice through a mechanism involving cellular free thiols," Journal of Nutrition, vol. 140, no. 6, pp. 1155-1161, 2010. 


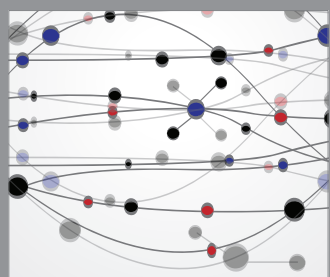

The Scientific World Journal
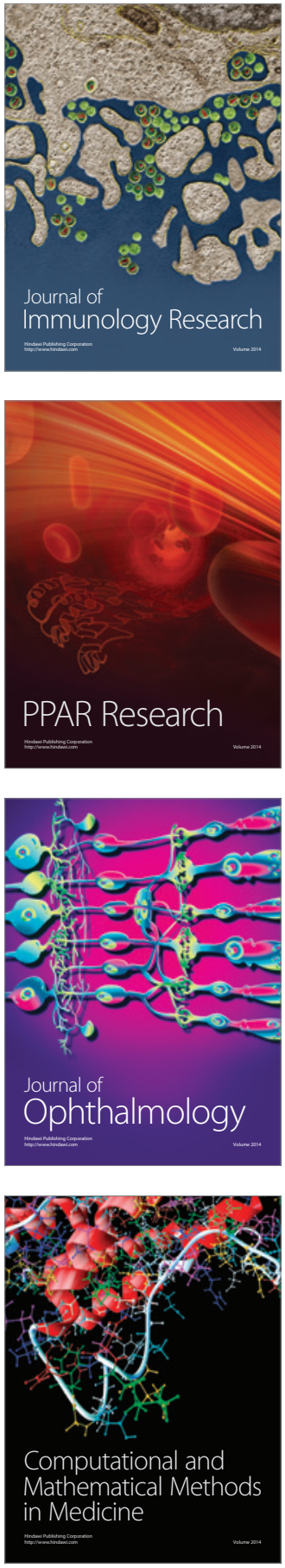

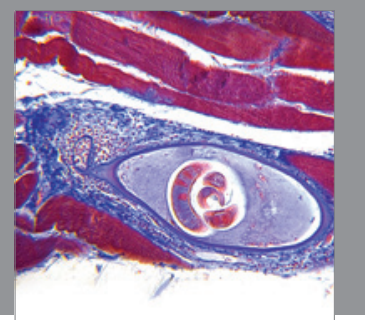

Gastroenterology

Research and Practice
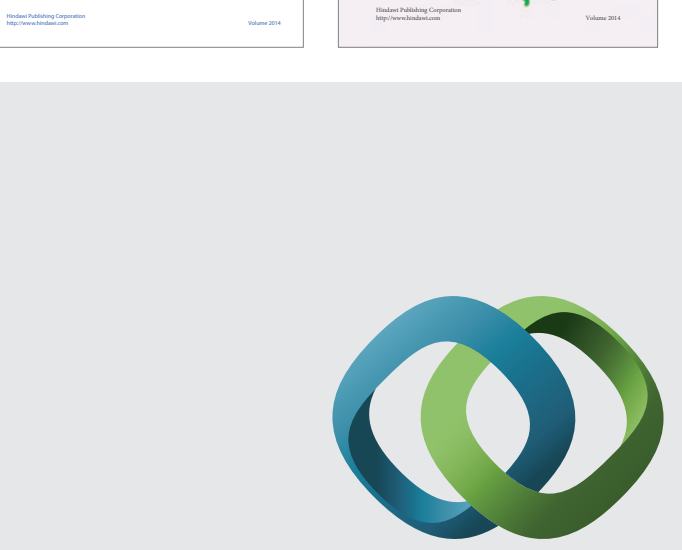

\section{Hindawi}

Submit your manuscripts at

http://www.hindawi.com
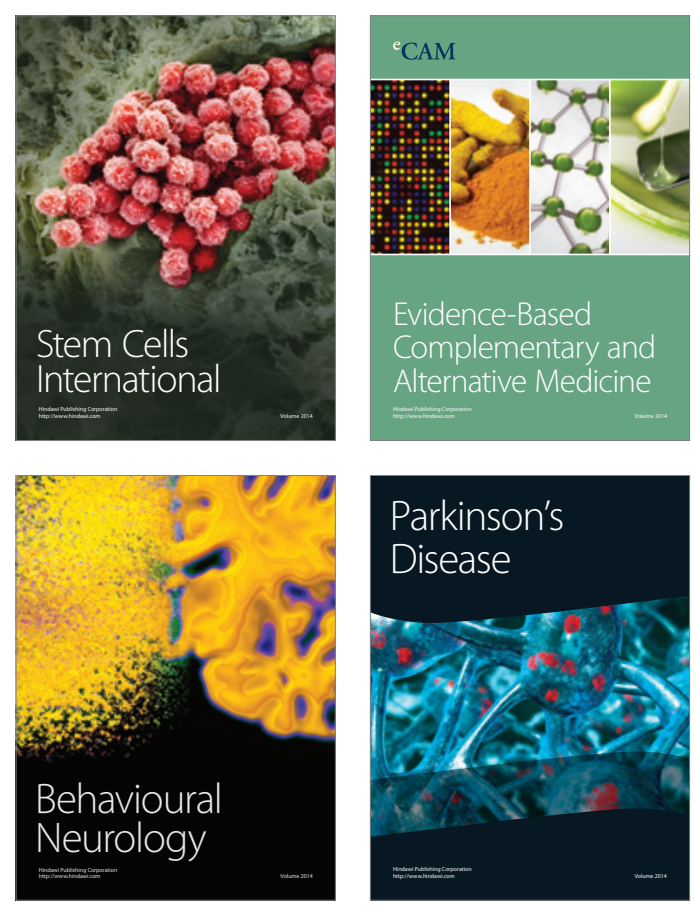

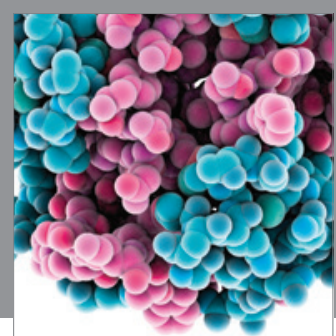

Journal of
Diabetes Research

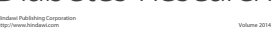

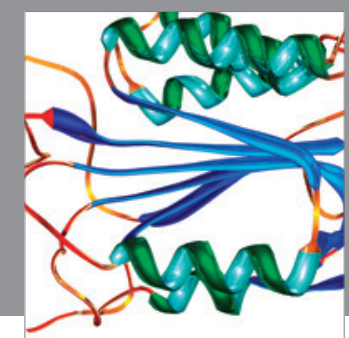

Disease Markers
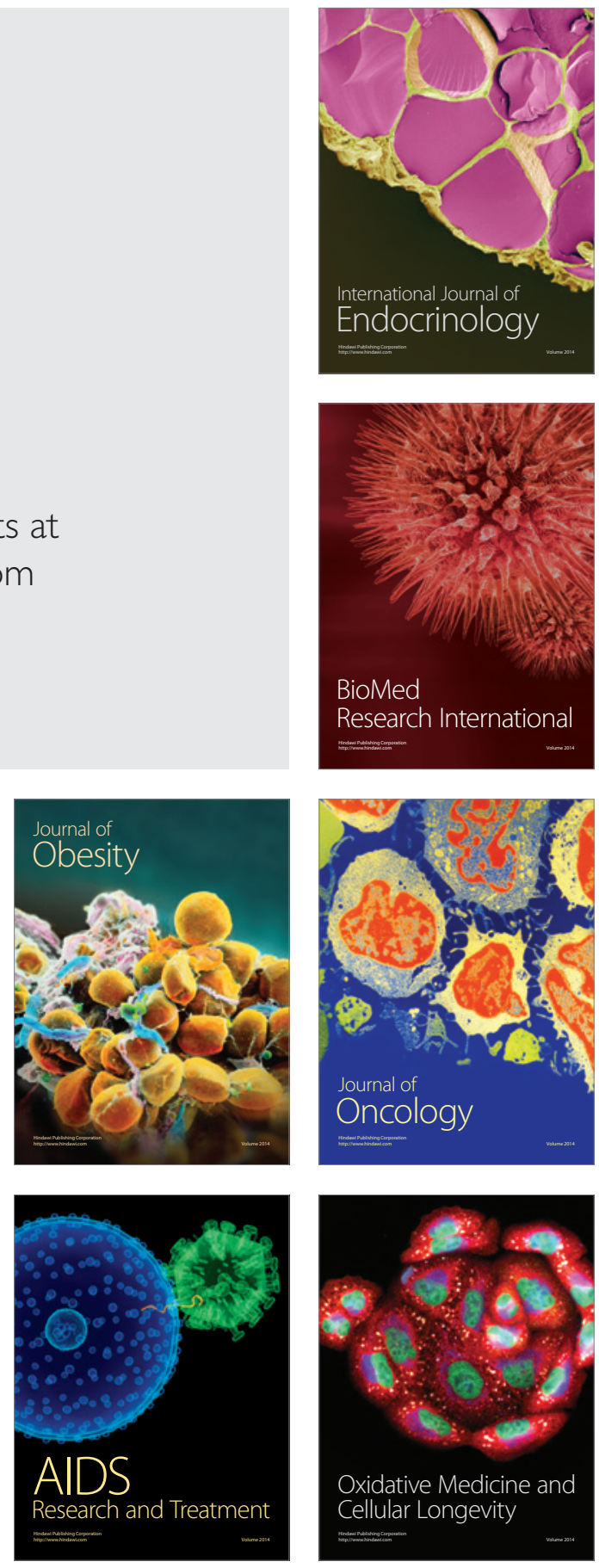